\title{
Undetached Parts and Disconnected Wholes
}

\author{
Achille C. Varzi \\ Department of Philosophy, Columbia University, New York
}

[Publication details TBA]

\section{Introduction}

The Doctrine of Potential Parts (DPP) says that undetached parts, i.e., proper parts that are connected to other parts of the same whole, are not actual entities. They are merely potential entities, entities that do not exist but would exist if they were detached from the rest. They are just aspects of the whole to which they belong, ways in which the whole could be broken down, and talk of such parts is really just talk about the modal properties of the whole. DPP is rooted in some writings of Aristotle and Aquinas ${ }^{1}$ and has received considerable attention, in one form or other, also among contemporary philosophers, including Ingvar Johansson (2006a, 2008). ${ }^{2}$ Here I offer a reconstruction of this doctrine and present an argument to illustrate its hidden kinship with another, parallel but independent doctrine- the Doctrine of Potential Wholes (DPW). According to this second doctrine, disconnected wholes too, i.e., wholes that are not in one piece, count as merely potential entities, entities that do not exist though they would exist if their parts were suitably conjoined. I offer a diagnosis of the parallelism and briefly examine its bearing on Johansson's views concerning the possibility of mereological change in the spirit of a common-sense metaphysics.

\footnotetext{
${ }^{1}$ See, for instance, Aristotle's Physics, VII.5, 250a24-25, and Metaphysics, VII.16, 1040b10-16, and Aquinas's In Metaphysicorum expositio, V, §1102. On the history of the doctrine, see Holden (2004: ch. 2) and Pasnau (2011: ch. 26).

${ }^{2}$ Other authors include van Inwagen (1981) and Olson (1995), though both insist more on the non-reality of undetached parts than on their potentiality (and van Inwagen only in regard to arbitrary undetached parts, as opposed to those that "constitute a life", such as cells in a human body). See also Casati \& Varzi (1999: ch. 6).
} 


\section{A Familiar Puzzle}

As I understand it, DPP is a negative doctrine concerning the ontological status of proper undetached parts. This is not to say that it regards proper parthood as incompatible with actual existence. For the friend of DPP, there is no question about the status of those parts that independently qualify as ordinary objects. Mary and her cat, Tibbles, are parts of their scattered mereological sum-they are proper parts thereof. Yet according to DPP they may well exist, if the sum exists. (And certainly they may exist even if the sum doesn't, in case one has problems with the ontological status of scattered objects.) Rather, what DPP denies is the existence of such proper parts as Mary's left hand, or Tibbles' tail. According to this doctrine, such objects of reference do not have that thingy character that distinguishes full-fledged integral wholes like Mary and Tibbles. They are not, therefore, to be included in an inventory of what there is along with the wholes to which they belong. A hand or a tail only exist in potentia.

One of the advantages of this doctrine is that it provides a simple solution to a classic puzzle that arises in connection with the mereology of enduring entitiesentities that persist through time by being wholly present at each time at which they exist. ${ }^{3}$ At time $t$, Tibbles is a happy cat with a nice tail. Then comes an accident in which Tibbles loses its tail (the tail may or may not be destroyed in the accident), and at time $t^{\prime}$ poor Tibbles is a tailless cat. Call the tail, 'Tail', and the remainder, 'Tib'. The puzzle is that the following four propositions are all prima facie true, yet they form an inconsistent set: ${ }^{4}$

(1) Tib at $t \neq$ Tibbles at $t$

(2) Tib at $t=$ Tib at $t^{\prime}$

(3) Tibbles at $t=$ Tibbles at $t^{\prime}$

(4) Tibbles at $t^{\prime}=$ Tib at $t^{\prime}$

The truth of (1) appears to follow directly by Leibniz's law, since before the accident Tib and Tibbles have different sizes, different shapes, etc.; (2) seems to be

${ }^{3}$ The puzzle has been introduced to contemporary philosophical discussion by Wiggins (1968), apparently drawing on Peter Geach. It was actually a common sophisma among the medievals, Animal est pars animalis, and can be traced back at least to Chrysippus and the Stoics; see e.g. Sedley (1982) and especially Bowin (2003). For a representative selection of contemporary literature devoted to the puzzle, see Rea (1997).

${ }^{4}$ The exact logical form of (1)-(4) is itself controversial, and Johansson (2008) argues that there may be no adequate way of representing it in standard first-order logic. For the purpose of this note, let us just agree that, for example, 'Tib at $t$ ' is meant to pick out the thing that, at time $t$, is Tib. 
true insofar as Tib is, after all, not affected by whatever happens to Tail; (3) reflects the common sense intuition according to which a cat can survive small changes, including the painful loss of the tail; and (4) comes with the intuition that after the accident Tib and Tibbles appear to be indistinguishable: same size, same shape, same location, same material constitution, etc. Yet, (2)-(4) jointly imply the negation of (1) via transitivity of identity, so something must go. Since (1) appears to be undeniable in virtue of purely logical considerations, it is generally argued that we must give up at least one among (2), (3), and (4). And to the extent that those propositions are also prima facie true, any such decision would come at a cost. Thus, to give up (4) is to abandon both the principle of mereological extensionality, according to which distinct entities cannot have exactly the same proper parts, along with the traditional identity criterion for material bodies, according to which distinct bodies cannot occupy the same place at the same time. To give up (3) leads eventually to a strong form of mereological essentialism according to which the removal of a single part, no matter how small or insignificant, affects the identity of the whole-and that flies in the face of common sense. So, if neither of these ways out is found palatable, the only option is to give up (2). But this seems to imply an even stronger form of essentialism - a form of topological essentialism to the effect that the removal of a part affects the identity of another, adjacent but mereologically disjoint part. And if one worries about mereological essentialism, why should one accept that? As already Philo of Alexandria put it (in his discussion of Chrysippus' suggestion that only Tibbles would survive the accident), how can it be that Tib, who has had no parts chopped off, has been snatched away, while Tibbles, whose tail has been amputated, has not perished ? $^{5}$

It is here that DPP offers a solution. For a defender of the doctrine, (2) is indeed false. But it is false for the important reason that Tib (like Tail) only comes

${ }^{5}$ See De Aeternitate Mundi, 48. For the record, the first option-giving up (4) - is the preferred way in the literature; see e.g. Wiggins (1979) and Simons (1987) for the denial of extensionality, Wiggins (1968) and Thomson (1983) for the denial of the principle of exclusive location, and Doepke (1982) for the denial of both. The second optiongiving up (3) —is Chisholm's (1973) favored strategy. The last option — giving up (2) -is not a popular one, but see e.g. Burke (1996). Of course, one remaining option would be to accept all of (1)-(4) but deny that identity is transitive: this is the step taken e.g. by Garrett (1985). (Geach 1967 and Noonan 1980 take identity to be relative to sortal terms, with similar results.) Alternatively, one could resist all these options by subscribing to a conception of objects as perduring entities, as in Heller (1984), or as processions of momentary stages, as in Sider (1996). The latter is, in fact, the view I hold; see Varzi (2003). However, here I'll stick to the puzzle as it arises with regard to the endurantist conception. 
into existence at $t^{\prime}$. Pace Philo, at $t$ Tib does not exist at all; it is merely possible that there be such an entity. So the phrase 'Tib at $t$ ' cannot have the same referent as 'Tib at $t$ ', which does stand for a full-fledged actual entity. No matter how tolerant one is with regard to the survival of entities through change, nothing can outlast a change from potentiality to actuality. For that is not, strictly speaking, a "change". As Barry Smith (2001:§5) puts it, it is the passage from something which is not a real substance to something which is a real substance. As Thomas Holden (2004:91) has it, actual division creates those parts as "freshly minted beings" - it does not simply unveil so many pre-existent things-in-waiting.

It also bears emphasis that if DPP is accepted, we have another, independent motivation for accepting proposition (1) — one that does not depend on Leibniz's law. If DPP is accepted, the truth of (1) is not just a matter of Tibbles and Tib having different properties. Rather, (1) is true for the simple reason that, at $t$, Tibbles exists whereas Tib does does not-it is not actual. This is indicative of the wide scope of DPP's consequences.

\section{A Different Story}

There is, however, a striking twist in the way of thinking about parts that underlies this doctrine. On the one hand, if a piece is still attached to a whole, it counts as a part thereof, though not as an actual entity. On the other hand, when a piece is detached from the whole, it counts as an actual entity, but it is no longer a part. This may not be true in general, but it certainly holds for the proper parts of such enduring entities as Tibbles, the cat. For, suppose the tail is not destroyed in the accident; it is cut off, but not a single molecule of it suffers from the cut. (Nothing important hinges on the presumption that the boundary between Tib and Tail be perfectly sharp.) Then, at $t$ Tail is a part of Tibbles, but it does not exist. At $t^{\prime}$, Tail exists, but it is no longer a part of Tibbles. At best, at $t^{\prime}$ Tail is part of the mereological sum of Tib and Tail, i.e., the whole composed of Tib and Tail, which is something else than Tibbles at $t^{\prime}$ (it has a different shape, a different location, etc.).

If this is correct, then another puzzle emerges. For let ' + ' denote the operation of mereological sum. Then we have:

$\left(1^{\prime}\right) \quad$ Tibbles at $t^{\prime} \neq$ Tib+Tail at $t^{\prime}$

(2') Tib+Tail at $t=$ Tib+Tail at $t^{\prime}$

(3') Tibbles at $t=$ Tibbles at $t^{\prime}$

(4') Tibbles at $t=\mathrm{Tib}+$ Tail at $t$

Again, each of these four propositions is prima facie true, yet their inconsistency is an immediate consequence of the transitivity of identity. Since $\left(1^{\prime}\right)$ is true by Leib- 
niz's law (as we have just seen, at $t^{\prime}$ Tibbles and Tib+Tail have different shapes, different locations, etc.), one must give up at least one among $\left(2^{\prime}\right),\left(3^{\prime}\right)$, and $\left(4^{\prime}\right)$. And, again, to give up (4') is to abandon both the principle of mereological extensionality and the traditional identity criterion for material bodies, while to give up $\left(3^{\prime}\right)(=(3))$ is to accept a strong form of mereological essentialism. So, again, if neither of these options is found palatable, we are left with the denial of $\left(2^{\prime}\right)$. This is not immediately comparable to the denial of proposition (2) in the earlier set, yet it still seems to entail a form of topological essentialism. After all, to deny Tib+Tail's survival is to make Tib+ Tail's existence depend on the topological property of self-connectedness, at least on the assumption that Tib and Tail do not undergo any internal change throughout the interval from $t$ to $t^{\prime}$. Indeed, if $\left(4^{\prime}\right)$ is accepted (so that Tib+Tail exists at $t$ ), the only plausible way to give up $\left(2^{\prime}\right)$ is to deny that Tib+Tail still exists at $t^{\prime}$. This, in turn, amounts to giving up the unrestricted principle of mereological fusion, to the effect that a sum always exists independently of the topological (or spatial at large) relationships between the parts. And in this case, there is no particular explanation that DPP can offer to justify this move. From the fact that undetached parts, such as Tib and Tail at $t$, are not actual entities it does not follow that their sum does not exist at $t$, given that Tibbles does. Indeed, if mereological extensionality is preserved, then Tibbles is the sum of Tib and Tail at $t$. Likewise, then, from the fact that those parts eventually get separated at $t^{\prime}$ it does not follow that their sum then ceases to exist. One needs an independent explanation for such a claim. And nothing is available to the defender of DPP that is not already available to those who hold other views.

It follows, then, that DPP is much weaker than consideration of (1)-(4) would suggest. The explanation afforded by DPP is local and only applies to the original puzzle. Alternatively, DPP must be strengthened by combining it with an explicit rejection of the fusion principle when it comes to disconnected parts. But note that this would make (1') true for a different reason than the one advertised through an appeal to Leibniz's law. The relevant identity between Tibbles and Tib+Tail would fail to hold because only one of these entities exists at $t^{\prime}$. This is perfectly analogous to the corresponding remark concerning (1), and it is perfectly legitimate in itself. But then DPP, the Doctrine of Potential Parts, turns into DPW, the Doctrine of Potential Wholes. Disconnected wholes would not be actual entities. They would be merely potential entities, entities that would exist if (or rather, only if) their parts were suitably conjoined. And this is quite a different story. ${ }^{6}$

\footnotetext{
${ }^{6}$ Smith $(1994, \S 3.5)$ treats DPP and DPW as two parts of the thesis of "mereological potentialism" he ascribes to Aristotle. Neither part, however, logically entails the other.
} 


\section{Parts, Wholes, and Functional Unities}

There is, I think, an important moral to be drawn from the argument just given, and it is a familiar one: a theory of parts is no theory of wholes. Absent the latter, any solution to the puzzle raised by (1)-(4) is in danger of misfiring when it comes to other ways in which the problem of mereological change may surface, leaving our philosophical views and common-sense intuitions up for grabs. To put it differently, DPP provides a robust way out of the original puzzle only insofar as the ontological status it attributes to undetached proper parts is grounded on a more general view concerning existence and individuality, a view about what there is that is general enough to account, too, for the status of disconnected wholes in the spirit of DPW.

There are, of course, theories that deliver such general views. A good example, in my opinion, is the theory articulated by Smith (2001), which is based on the fundamental distinction between fiat and bona fide boundaries, i.e., boundaries that do and boundaries that do not depend on our cognitive and social acts. ${ }^{7}$ For Smith, only entities endowed with complete exterior boundaries of the bona fide sort count as full-fledged individual substances. Tibbles at $t$ or Tib and Tail at $t^{\prime}$ are good cases in point. But neither undetached proper parts, such as Tib and Tail at $t$, nor disconnected wholes, such as Tib+Tail at $t^{\prime}$, pass muster-the former because a human fiat is involved in the process whereby those parts are delineated or "carved out" of the larger bona fide objects to which they belong; the latter because a fiat act on our part is similarly involved in the process whereby two or more bona fide objects are unified together into a larger whole. We have a general view on what counts as a genuine substance, and both DPP and DPW follow from that general view as (important) corollaries.

The problem with this theory, as I see it, is that it rests too critically on the assumption that the fiat / bona fide opposition aligns well with our pre-analytical intuitions, an assumption that cries for argument. It's not just that there is some awkwardness in the thought that everything comes with a boundary, i.e., effectively, a surface. (As John Austin (1962:100) famously complained, where and what exactly is the surface of a cat?) And it's not just that there is some vagueness always lurking in the background. (To use an example from Schulz \& Johansson (2007:515), suppose Tibbles is eating; when exacly does the food become part of her? After some chewing? When she swallows it? At the end of the digestive process?) Rather, the problem is that in most cases, if not all cases, what look like

\footnotetext{
${ }^{7}$ On this distinction, see also Smith \& Varzi (2000).
} 
bona fide boundaries turn out to involve fiat elements of some sort. ${ }^{8}$ For surely, as we know, a cat is not a solid, continuous substance. On closer look, ordinary material bodies are just swarms of tiny particles frantically dancing in empty space, and speaking of their outer boundaries is like speaking of the "flat top" of a fakir's bed of nails, as Peter Simons (1991:91) put it. On closer look, it makes little sense to speak of ordinary material bodies as demarcated by unitary, mind-independent, bona fide boundaries. Their boundaries involve a lot of gap-bridging. They involve the same degree of idealization of a drawing obtained by "connecting the dots", the same degree of arbitrariness as any mathematical graph smoothed out of scattered and inexact data, the same degree of abstraction as the figures' contours in a Seurat painting. On closer look, therefore, even the boundary of Tibbles the cat has the ephemeral status of a fiat demarcation that exists in virtue of our cognitive acts and decisions. And what goes for Tibbles goes for everything. Even stars? asked Israel Sheffler (1980:205). Yes, even stars - answered Nelson Goodman (1983:104): "As we make constellations by picking out and putting together certain stars rather than others, so we make stars by drawing certain boundaries rather than others". None of this affects the candidacy of Smith's theory as the right kind of theory vis-à-vis the intimate link between DPP and DPW. But the worry is serious: to the extent that everything may be seen as a fiat object of some sort, everything will count as a potential entity in the relevant sense and the theory won't get off the ground.

Now, Ingvar Johansson (2006a, 2008) offers an alternative view. He does see the possession of a bona fide boundary as a requirement for something to count as a substance, and he doesn't think that the worry I have just outlined is a serious one (as opposed to a "curious" one: see (2006a: 17)). However, on his view the real meat is elsewhere. Building on Jonathan Lowe's (1989) neo-Aristotelian framework, Johansson takes the central mark of a substance to lie in the possession a certain kind of functional unity, i.e., a form in the old Aristotelian sense of this word. In particular, a material substance is always a unity superimposed on some matter, albeit not necessarily the same matter all the time. For example, a cat such as Tibbles gets its nature from a certain natural-kind functional unity (intuitively: being a cat), superimposed on a certain amount of feline tissue. Not all matter, however, comes with a form in the relevant sense, and when it doesn't, we have at most a potential substance. ${ }^{9}$ Exactly when this is the case is no straight-

\footnotetext{
${ }^{8}$ Here I draw on Varzi (2011).

${ }^{9}$ Johansson's earlier works draw also on the notion of ontological dependence, yielding a different account of the opposition between actual and potential entities. See e.g.
} 
forward business, and I intend to come back to this. But at least with respect to our first case study, the outcome of Johansson's theory is clear enough: at $t$, Tib and Tail count as merely potential in this sense, whereas they both count as actual substances at $t^{\prime}$, after they have been physically separated. As a result, the theory vindicates DPP and proposition (2) in the initial set is discarded as false: "a potential functional unity cannot be identical with an actual functional unity" (2008:224). By contrast, proposition (3), which asserts the numerical identity of Tibbles at $t$ and at $t^{\prime}$, is true as long as Tibbles does indeed get its nature from a functional unity of the kind being a cat (as opposed to, say, being a cat with a tail). Johansson may thus conclude that the account solves the puzzle while accommodating the common-sense view according to which a cat that loses its tail does not ipso facto lose its identity.

What about the propositions that make up our second set, $\left(1^{\prime}\right)-\left(4^{\prime}\right)$ ? Does Johansson's metaphysics vindicates DPW as well, thus rejecting $\left(2^{\prime}\right)$ and blocking the relevant puzzle accordingly? Here is where things get tricky. Lowe himself (1989: ch. 6) is explicit in rejecting mereological extensionality and blocking the argument at (4'), drawing a categorial distinction between genuine integral wholes, such as Tibbles the cat, and mere sums of parts, such as Tib+Tail. His reasons are not unfamiliar: while the former supposedly survive the destruction of at least some of their parts (which is why (3) and ( $\left.3^{\prime}\right)$ are true), the latter do not. I take it that Johansson agrees, though in his writings the denial of extensionality is not quite as explicit (at least as far as I know). ${ }^{10}$ But Lowe also draws a further categorial distinction between mere sums and aggregates, i.e., things such as heaps and lumps: while the latter do not survive scattering, the former do. Since Tib+Tail is by definition a sum, not an aggregate, and since we are assuming that Tail is not destroyed in the accident, so that at $t^{\prime}$ Tib and Tail are simply detached, this means that on Lowe's metaphysics Tib+Tail does exist at $t^{\prime}$ just as it exists at $t$, hence that $\left(2^{\prime}\right)$ is true after all. In other words, Lowe's metaphysics does not support DPW, in spite of any sympathies it might have for DPP. ${ }^{11}$ Does Johansson's theory, which is meant to build on Lowe's, inherit this feature?

Johansson (1989), esp. chs. 9 and 14. Here, however, I will focus exclusively on his more recent writings.

${ }^{10}$ Johansson (2008:222) does say that "cats are more than the molecules that constitute them" (which is why he rejects "the "flat' (molecule) representation" of the puzzle: p. 224). This amounts to a denial of the thesis known as "composition as identity" (Lewis 1991: 81-87), which is closely related, but not equivalent, to mereological extensionality.

${ }^{11}$ It is, in fact, unclear whether it fully supports DPP. With respect to the original puzzle in (1)-(4), Lowe would indeed block the argument at step (2), but on account of 
This is a question that I find remarkably difficult to answer. On one plausible construal, a disconnected sum is just as devoid of a functional unity as an undetached part. The matter is there-disconnected in one case, connected in the other-but only as a potentiality for a form-matter unity. There is a temptation to say that, while in the case of an undetached part such as Tib at $t$ the form is not yet there, in the case of a disconnected whole such as Tib+Tail at $t^{\prime}$ the form is no longer there. But I think this is just a temptation stemming from the contingencies of story under consideration. Generally speaking, Tib and Tail can still be joined back together, so to speak, thereby vindicating the sense in which their sum is, at $t^{\prime}$, a potential substance. If so, then the same reasons that in Johansson's theory entail DPP will entail DPW, which is exactly how it should be, pace Lowe. On the other hand, this construal makes the theory depend crucially on the metaphysical principles that govern the instantiation relation. Johansson (2008:223) takes it as an axiom that whenever there is an instance of a certain form, there is also an instance of some kind of matter as well as an instance of the corresponding formmatter unity. This is helpful. But we also need an axiom that says how things work in the opposite direction. We need explicit criteria for determining under what conditions the existence of an instance of some kind of matter entails the existence of a certain form, specifically of a form that is suitable for delivering a corresponding form-matter unity - a bona fide substance. Absent a clear specification of those conditions, DPW is up for grabs and the DPP-based solution to the puzzle raised by (1)-(4) does not extend to the kindred puzzle raised by $\left(1^{\prime}\right)-\left(4^{\prime}\right)$.

My understanding is that such conditions will broadly be determined by the general theory of natural kinds that must be assumed in the background, and in terms of which Johansson illustrates the rich notion of functional unity that he has in mind. I would not, in fact, be surprised if such a theory ruled out forms that would have to be instantiated in conjunction with disconnected portions of matter, thereby vindicating DPW over and above DPP. But I am not so sure. After all, Johansson is engaged in the difficult task of doing justice to common-sense metaphysical intuitions, and common sense does have room (and names) for forms that can be so instantiated - things such as the Big Dipper, a bikini, my three-volume copy of Principia Mathematica, or (to use an example from Johansson (2006b)) tokens of the "smiley" sign composed of a colon and a right parenthesis. What about Tib+Tail at $t^{\prime}$ ?

the fact that Tib is not an "independently individuable" object on a par with Tibbles (1986: 95). It is not clear whether this means that Tib does not actually exist at $t$, though Lowe comes close to saying this — and to DPP — in (2002: 75-76). 


\section{References}

Austin, J. L. (1962). Sense and Sensibilia (ed. by G. J. Warnock), Oxford: Oxford University Press.

Bowin, J. (2003). "Chrysippus' Puzzle About Identity", Oxford Studies in Ancient Philosophy, 24: 239-251.

Burke, M. B. (1996). "Tibbles the Cat: A Modern Sophisma", Philosophical Studies, 84: 63-74.

Casati, R., and Varzi, A. C. (1999). Parts and Places. The Structures of Spatial Representation, Cambridge (MA): MIT Press.

Chisholm, R. M. (1973). "Parts as Essential to Their Wholes", Review of Metaphysics, 26: 581-603.

Doepke, F. C. (1982). "Spatially Coinciding Objects", Ratio, 24: 45-60.

Garrett, B. J. (1985). "Noonan, 'Best Candidate' Theories, and the Ship of Theseus", Analysis, 45: 12-15.

Geach, P. T. (1967). "Identity", Review of Metaphysics, 21: 3-12.

Goodman, N. (1983). "Notes on the Well-Made World", Erkenntnis, 19: 99-108.

Heller, M. (1984). “Temporal Parts of Four Dimensional Objects”, Philosophical Studies, 46: 323-334.

Holden, T. (2004). The Architecture of Matter. Galileo to Kant, Oxford: Oxford University Press.

Johansson, I. (1989). Ontological Investigations. An Inquiry into the Categories of Nature, Man and Society, London: Routledge (2nd ed., Frankfurt: Ontos Verlag, 2004).

Johansson, I. (2006a). "Identity Puzzles and Supervenient Identities", Metaphysica, 7: 733.

Johansson, I. (2006b). "Inference Rules, Emergent Wholes and Supervenient Properties", TripleC, 4: 127-135.

Johansson, I. (2008). "Formalizing Common Sense: An Operator-Based Approach to the Tibbles-Tib Problem", Synthese, 163: 217-225.

Lewis, D. K. (1991). Parts of Classes, Oxford: Basil Blackwell.

Lowe, E. J. (1989). Kinds of Being. A Study of Individuation, Identity and the Logic of Sortal Terms, Oxford: Basil Blackwell.

Lowe, E. J. (2002). A Survey of Metaphysics, Oxford: Oxford University Press.

Noonan, H. W. (1980). Objects and Identity, The Hague: Nijhoff.

Olson, E. T. (1995). "Why I Have No Hands", Theoria, 61: 182-197.

Pasnau, R. (2011). Metaphysical Themes 1274-1671, Oxford: Clarendon.

Rea, M., ed. (1997). Material Constitution. A Reader, Lanham, MD: Rowman \& Littlefield.

Scheffler, I. (1980). “The Wonderful Worlds of Goodman”, Synthese, 45: 201-209.

Schulz, S., and Johansson, I. (2007). "Continua in Biological Systems", The Monist, 90: 499-522. 
Sedley, D. (1982). "The Stoic Criterion of Identity”, Phronesis, 27: 255-275.

Sider, T. (1996). "All the World's a Stage”, Australasian Journal of Philosophy, 74: 433453.

Simons, P. M. (1987). Parts. A Study in Ontology, Oxford: Clarendon.

Simons, P. M. (1991). "Faces, Boundaries, and Thin Layers", in A. P. Martinich and M. J. White (eds.), Certainty and Surface in Epistemology and Philosophical Method. Essays in Honor of Avrum Stroll, Lewiston: Edwin Mellen Press, 87-99.

Smith, B. (1994). Austrian Philosophy. The Legacy of Franz Brentano, La Salle, IL: Open Court.

Smith, B. (2001). "Fiat Objects", Topoi, 20: 131-148.

Smith, B., and Varzi, A. C. (2000). "Fiat and Bona Fide Boundaries", Philosophy and Phenomenological Research, 60: 401-420.

Thomson, J. J. (1983). "Parthood and Identity Across Time", Journal of Philosophy, 80: 201-220.

van Inwagen, P. (1981). "The Doctrine of Arbitrary Undetached Parts", Pacific Philosophical Quarterly, 62: 123-137.

Varzi, A. C. (2003). "Naming the Stages", Dialectica 57: 387-412.

Varzi, A. C. (2011). "Boundaries, Conventions, and Realism", in J. K. Campbell, M. O'Rourke, and M. H. Slater (eds.), Carving Nature at Its Joints: Natural Kinds in Metaphysics and Science, Cambridge (MA): MIT Press, 129-153.

Wiggins, D. (1968). "On Being in the Same Place at the Same Time", Philosophical Review, 77: 90-95.

Wiggins, D. (1979). "Mereological Essentialism: Asymmetrical Essential Dependence and the Nature of Continuants", Grazer philosophische Studien, 7: 297-315. 